\title{
PENGGUNAAN ADVERBIA ICHIOU DALAM NOVEL SERI REIKAN KENTEI DAN KIOKUYA DILIHAT DARI SUDUT PANDANG "PARTISIPAN"
}

\author{
Tsaniatilwadai Anugrah \\ Musashi University \\ tsaniatilwada@gmail.com
}

\begin{abstract}
The purpose of this research is to find out the use of the ichiou adverb in the speech situations from participants with sociolinguistic approach. The method used in this research is descriptive method with qualitative analysis. Data sources are novels. The data collection of this study is choosing a sentence containing the ichiou adverb from six novels. As for some conclusions from the results of this research depend on the the use of the ichiou adverb is most influencing by participant's social status.
\end{abstract}

Keywords: Ichiou adverb, sociolinguistics, participant

Abstrak

Tujuan dalam penelitian ini yakni untuk mengetahui penggunaan adverbia ichiou dalam beberapa situasi percakapan ditinjau dari penggunanya dengan pendekatan sosiolinguistik. Metode yang digunakan merupakan metode analisis kualitatif. Sumber data yang digunakan berasal dari novel, sedangkan data dikumpulkan berdasarkan percakapan yang terdapat dalam novel seri Reikan Kentei dan Kiokuya. Beberapa hasil analisis menunjukkan bahwa sosial status partisipan memengaruhi penggunaan adverbia ichiou dalam suatu percakapan.

Kata kunci: adverbia ichiou, sosiolinguistik, partisipan

\section{PENDAHULUAN}

Akhir-akhir ini banyak anak muda belajar bahasa Jepang dengan beberapa tujuan. Misalnya untuk keperluan kerja, sekolah, atau banyak hal lain lagi. Ambil contoh di Indonesia, masyarakat cenderung memilih belajar bahasa Jepang. Salah satu alasan dari itu adalah karena banyak perusahaan Jepang didirikan di Indonesia. Selain itu juga karena banyak masyarakat Indonesia yang terobsesi dengan Jepang dan gaya hidupnya.
Pada percakapan sehari-hari kita selalu menggunakan bahasa tergantung siapa lawan bicaranya. Seringkali kita menggunakan bahasa formal untuk orang yang lebih tua atau kepada orang yang jabatannya lebih tinggi dibandingkan kita (Febrianty, et all: 2015). Selain itu, kita mengunakan bahasa informal untuk keluarga kita, teman atau orang-orang yang sudah kenal lama. Sasaki (1996) menjelaskan bahwa dalam percakapan bahasa Jepang, adverbia ichiou dapat mengubah makna sesuai dengan 
penyampaiannya dan lawan bicaranya.

Sementara itu, adverbia ichiou mengandung arti yang ambigu atau yang disebut dengan aimai dalam bahasa Jepang. Arti yang ambigu dapat dilihat seperti pada percakapan berikut ini:

1） A：「君、資料は読んだのか ね」

B:「ええ、いちおうは...」

\section{A：「一応も二応もない。も} う一度ちゃんと読んで来

\section{い」}

A: Kimi, shiryou wa yondanokane?

B: Ee, ichiou wa...

A: Ichiou mo niou mo nai. Mou ichido chanto yondekoi

A: Apakah kamu sudah membaca datanya?

B: Ya, secara keseluruhan saja...

A: Bukan ichiou atau niou(Tidak perlu beralasan lagi).

Baca lagi dengan serius.

(Yoshifumi dan Hideko:1994)

Dalam percakapan tersebut dijelaskan bahwa si B menjawab pertanyaan si A dan si B menjawab hanya mengerjakan secara keseluruhan saja. Jawaban dari si B menyinggung si A karena A merasa diremehkan. Kata "Ichiou mo ni ou mo nai" merupakan metafora yang dapat diartikan menjadi "Tidak perlu beralasan lagi”.

Dari percakapan tersebut dapat dietahui bahwa adverbia ichiou dapat memberikan kesan meremehkan pekerjaan seseorang maka akan memberikan kesan kurang sopan ketika digunakan untuk orang yang memiliki jabatan yang lebih tinggi dari penutur.

Berdasarkan hal tersebut, penulis tertarik untuk meneliti hubungan antara partisipan atau pengguna bahasa dengan adverbia ichiou.

Hymes (1990) menyatakan bahwa setiap percakapan tidak akan berjalan jika tidak ada beberapa komponen penting. Komponen penting tersebut dijadikan sebuah akronim "SPEAKING” yang terdiri dari Setting and scene (Latar), Participants (partisipan), Ends (tujuan dari percakapan), Act of sequence (Kegiatan yang timbul), Key (Nada bicara), Instruments (Instrumen yang digunakan), Norms (Norma yang terkandung dalam percakapan), dan Genres (Bentuk komunikasi). 
Penelitian ini hanya meneliti pada sisi partisipan saja. Komponen Partisipan (P) memiliki variasi untuk kombinasi seperti penutur-pendengar, atau pengirimpenerima. Variasi ini mewakili beberapa peranan pada suatu sosial masyarakat. Percakapan untuk dua orang melibatkan satu orang penutur dan satu orang untuk pendengar yang dapat berubah peran sesuai dengan situasi, sebuah 'omelan' melibatkan penutur dan pendengar tanpa berubah peran, pidato politik melibatkan seorang pembicara dan yang dituju (penonton), selain itu juga percakapan melalui telepon tentunya melibatkan pengirim dan penerima (Hymes :1990).

\section{METODE}

$$
\text { Peneliti menggunakan }
$$
metode deskriptif dengan analisis kualitatif. Data di analisis dengan pendekatan sosiolinguistik dengan menggunakan teori Hymes mengenai SPEAKING untuk memecahkan beberapa rumusan masalah yang berhubungan dengan pengguna bahasa dan dijelaskan pada pembahasan berupa tabel dan kalimat.
Penulis mengumpulkan data dengan studi pustaka. Adapun beberapa metode analisis seperti berikut ini:

a. Mengumpulkan data dengan bentuk percakapan yang mengandung adverbia ichiou yang terdapat pada novel sebagai sumber data.

b. Mengelompokkan kalimat yang mengandung adverbia ichiou berdasarkan partisipan atau penggunanya. Hasil diubah dari kalimat menjadi kartu data.

c. Menganalisis data yang sudah dikelompokkan

d. Membuat kesimpulan

Data-data yang telah dianalisis akan ditampilkan pada bagian hasil dan diskusi berupa tabel dan kalimat.

\section{HASIL DAN DISKUSI}

Bagian ini menjelaskan hasil diskusi yang berisi adverbia ichiou berdasarkan partisipannya. Selain itu, membahas juga arti dari beberapa kalimat yang mengandung adverbia ichiou dari sumber data novel karya Kyouya Origami yang berjudul Reikan Kentei dan Kiokuya.

Sumber data yang digunakan merupakan novel karena novel merupakan cerminan dari kehidupan 
nyata dan terdapat percakapan tertulis yang relatif banyak dibandingkan dengan karya seperti komik yang lebih banyak mengungkapkan ekspresi dengan gambar daripada percakapan.

Data yang didapat berjumlah dua puluh empat, diantaranya dua belas data merupakan hasil pengumpulan dari novel seri Reikan Kentei, kemudian dua belas data didapat dari novel seri Kiokuya.

\section{a. Jenis kelamin}

Hasil analisis dapat dilihat pada tabel 1 berikut ini:

Tabel 1

Jenis Kelamin Tokoh (Reikan Kentei)

\begin{tabular}{|l|l|l|c|}
\hline No. & Nama & $\begin{array}{l}\text { Jenis } \\
\text { Kelamin }\end{array}$ & Frekuensi \\
\hline 1. & $\begin{array}{l}\text { Ayumu } \\
\text { Natsume }\end{array}$ & Pria & 2 \\
\hline 2. & $\begin{array}{l}\text { Haruka } \\
\text { Tsutsui }\end{array}$ & Pria & 1 \\
\hline 3. & $\begin{array}{l}\text { Haruomi } \\
\text { Batsu }\end{array}$ & Pria & 1 \\
\hline 4. & $\begin{array}{l}\text { Mawatari } \\
\text { Sensei }\end{array}$ & Pria & 1 \\
\hline 5. & $\begin{array}{l}\text { Shuji } \\
\text { Fujimoto }\end{array}$ & Pria & 1 \\
\hline 6. & Sora Hatori & Wanita & 0 \\
\hline 7. & Yukana & Wanita & 0 \\
\hline
\end{tabular}

Pada novel Reikan Kentei novel, Reikan Kentei Shinrei Aidoru no
Yuutsu dan Reikan Kentei Haru ni shite Kimi wo Hanare ditemukan lima tokoh pria bernama Shuji Fujimoto, Batsu, Natsume, Tsutsui dan Mawatari yang menggunakan adverbia ichiou dalam percakapannya, namun adverbia ichiou tidak digunakan oleh dua tokoh perempuan.

Hasil analisis untuk novel Kiokuya dapat dilihat pada tabel 2 berikut ini :

Tabel 2

Jenis Kelamin Tokoh(Kiokuya)

\begin{tabular}{|l|l|l|c|}
\hline No. & Nama & $\begin{array}{l}\text { Jenis } \\
\text { Kelamin }\end{array}$ & Frekuensi \\
\hline 1. & Inose & Pria & 1 \\
\hline 2. & Mariya & Pria & 1 \\
\hline 3. & Nanami & Wanita & 0 \\
\hline 4. & Natsuki & Wanita & 0 \\
\hline 5. & Ryoichi & Pria & 1 \\
\hline 6. & Takahara & Pria & 1 \\
\hline 7. & Tonomura & Pria & 2 \\
\hline
\end{tabular}

Dalam novel seri Kiokuya, Kiokuya II dan Kiokuya III ditemukan lima tokoh pria yang menggunakan adverbia ichiou dalam percakapan. Sama seperti hasil analisis novel seri sebelumnya, novel seri Kiokuya tidak ditemukan tokoh wanita yang menggunakan adverbia ichiou. 
Diketahui bahwa adverbia ichiou banyak digunakan pria karena pria memiliki kebiasaan menggunakan bahasa yang cenderung lebih praktis dan sederhana sesuai dengan pernyataan Kei (2013). Dapat disimpulkan bahwa adverbia ichiou sering digunakan oleh kaum pria dibandingkan dengan kaum wanita.

\section{Status Sosial}

Hasil analisis dari novel Reikan Kentei dapat dilihat sebagai berikut:

Tabel 3

Status Tokoh (Reikan Kentei)

\begin{tabular}{|l|l|l|c|}
\hline \multicolumn{1}{|c|}{ No. } & \multicolumn{1}{|c|}{ Nama } & Status & Frekuensi \\
\hline 1. & $\begin{array}{l}\text { Ayumu } \\
\text { Natsume }\end{array}$ & murid & 2 \\
\hline 2. & Haruka Tsutsui & murid & 1 \\
\hline 3. & Haruomi Batsu & murid & 1 \\
\hline 4. & $\begin{array}{l}\text { Mawatari } \\
\text { Sensei }\end{array}$ & Guru & 1 \\
\hline 5. & $\begin{array}{l}\text { Shuji Fujimoto } \\
\text { murid }\end{array}$ & 1 \\
\hline 6. & Sora Hatori & murid & 0 \\
\hline 7. & Yukana & murid & 0 \\
\hline
\end{tabular}

Dari novel Reikan Kentei, Reikan Kentei Shinrei Aidoru no Yuutsu and Reikan Kentei Haru ni Shite Kimi wo Hanare, dapat diketahui bahwa pengguna adverbia ichiou dalam novel Reikan Kentei berasal dari murid, namun disamping itu juga terdapat guru yang menggunakan aderbia ichiou, yaitu Mawatari. Untuk selengkapnya dapat disimak dari salah satu data dari kartu data di bawah ini.

Data 1

伐：「大体うちの学校はバイト禁止 だ！特例として認めてもらうには申請 が必要だって転入手続きするとき聞か なかったのかバカ」

修司 :「もうちょっと人に優しいしゃ ベり方ができへんのかおまえ

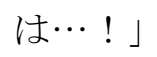

馬渡：「まあまま落ち着け。一刻も早 く辞めるのはおまえのためだとは思う けどな、まあ二応忠告はした。

Batsu:

Daitai Uchino Gakko ha baito kinshida! Tokureitoshite mitometemorau niha shinsei ga hitsuyou datte tennyutetsuzuki surutoki kikanakattanoka baka.

Shuji: Mou chotto hitoni yasashi syaberikata ga dekihennoka omaeha..!

Mawatari: Maa maa ochitsuke. Ikkokumo hayaku yamerunoha omaenotamedatoha omoukedona, maa ichiou chukokuha shita.

Batsu: Udah tahu di sekolah ini dilarang baito ( kerja paruh waktu)! Kan sudah diberi tahu sewaktu pindah 
sekolah jika untuk pengecualian harus meminta izin dulu, tidak didengarkan, bodoh.

Shuji: Kau memangnya tak bisa berbicara pakai bahasa yang lebih halus hah..!

Mawatari: Sudah sudah tenanglah. Secepat mungkin berhenti dari pekerjaan paruh waktu itu saya pikir demi kamu juga. Ya setidaknya saya sudah memberi tahu kamu.

Dalam data 1 ini terdapat partisipan, Mawatari sebagai penutur yang menggunakan adverbia ichiou, Shuji Fujimoto dan Batsu Haruomi sebagai mitra tutur.Dalam percakapan tersebut, Mawatari sedang memberi peringatan kepada muridnya yaitu Shuji Fujimoto dan Haruomi Batsu yang sedang ribut di kelas mengenai Shuji yang melakukan kerja paruh waktu namun sangat membahayakan nyawanya.

Jika dilihat dari status sosial, diketahui bahwa terdapat penggunaan adverbia ichiou oleh Mawatari yang memiliki status sebagai guru, digunakan kepada Shuji Fujimoto dan Batsu Haruomi yang memiliki status sebagai murid.

Selain data 1 , terdapat data 2, 5,9,11, 12 yang penuturnya menggunakan adverbia ichiou kepada mitra tutur yang memiliki status sosial sama dengan penuturnya.

Selanjutnya hasil analisis dari novel kiokuya dapat dilihat sebagai berikut:

Tabel 4

Status Tokoh (Kiokuya)

\begin{tabular}{|l|l|l|c|}
\hline \multicolumn{1}{|c|}{ No. } & Nama & Status & Frekuensi \\
\hline 1. & Inose & Jurnalis & 1 \\
\hline 2. & Mariya & Koki & 2 \\
\hline 3. & Nanami & murid & 0 \\
\hline 4. & Natsuki & murid & 0 \\
\hline 5. & Ryoichi & murid & 1 \\
\hline 6. & Takahara & Pengacara & 1 \\
\hline 7. & Tonomura & Asisten RT & 2 \\
\hline
\end{tabular}

Dalam novel Kiokuya, Kiokuya II, dan Kiokuya III, tokoh yang menggunakan adverbia Ichiou hanya satu dengan status sosial murid, satu sebagai koki, satu tokoh sebagai jurnalis satu tokoh sebagai asisten rumah tangga dan sebagai pengacara. Untuk lebih lengkap lagi, dapat disimak dari data berikut ini.

Data 17

17. 高原：「君が作ったわけ?」

外村：「一応…」

高原：「ふーん。あ、ありがとこれ」 
Takahara: Kimi ga tsukuttawake?

Tonomura: Ichiou...

Takahara: Hu-n. A, arigato kore.

Takahara: Ini kamu yang bikin?

Tonomura: Iya sih ( seadanya)...

Takahara: Hmm. Ah, makasih ya ini.

Pada data 17 ini terdapat partisipan, Takahara sebagai penutur yang menggunakan adverbia ichiou dan Tonomura sebagai mitra tutur.

Dalam percakapan tersebut Takahara sebagai pelanggan sebuah restoran yang menanyakan siapa penyaji hidangan yang ia makan kepada Tonomura yang saat itu bekerja sebagai pelayan. Jika dilihat dari status sosialnya, adverbia ichiou digunakan oleh Takahara yang status sosialnya lebih tinggi dibandingkan dengan Tonomura yang berstatus sebagai pelayan restoran.

Selain data 17 , terdapat data 18 dan data 21 yang penuturnya memiliki status sosial lebih tinggi dibandingkan mitra tuturnya. Sedangkan pada data 14 dan 16 penutur dan mitra tutur memiliki status sosial sama.

Selanjutnya akan dibahas mengenai partisipan jika dilihat dari rentang usianya.

\section{Usia}

Kisaran usia tokoh dapat dilihat dari tabel berikut ini:

Tabel 5

Usia Tokoh (Reikan Kentei)

\begin{tabular}{|l|l|l|c|}
\hline \multicolumn{1}{|c|}{$\begin{array}{c}\text { No } \\
\text { 1. }\end{array}$} & \multicolumn{1}{|c|}{ Nama } & \multicolumn{1}{c|}{ Usia } & Frekuensi \\
Natsume & Remaja & 2 \\
\hline 2. & Haruka Tsutsui & Remaja & 1 \\
\hline 3. & Haruomi Batsu & Remaja & 1 \\
\hline 4. & $\begin{array}{l}\text { Mawatari } \\
\text { Sensei }\end{array}$ & Dewasa & 1 \\
\hline 5. & Shuji Fujimoto & Remaja & 1 \\
\hline 6. & Sora Hatori & Remaja & 0 \\
\hline 7. & Yukana & Remaja & 0 \\
\hline
\end{tabular}

Tabel 6

Usia Tokoh (Kiokuya)

\begin{tabular}{|l|l|l|c|}
\hline No. & \multicolumn{1}{|c|}{ Nama } & \multicolumn{1}{c|}{ Usia } & Frekuensi \\
\hline 1. & Inose & Dewasa & 2 \\
\hline 2. & Mariya & Remaja & 2 \\
\hline 3. & Nanami & Remaja & 0 \\
\hline 4. & Natsuki & Remaja & 0 \\
\hline 5. & Ryoichi & Remaja & 1 \\
\hline 6. & Takahara & Dewasa & 1 \\
\hline & Tonomura & Dewasa & 2 \\
\hline
\end{tabular}

Partisipan pada novel umumnya dari usia remaja. Pada novel Reikan Kentei, Reikan Kentei Shinrei Airodu no Yuutsu dan Reikan Kentei Haru ni Shite Kimi wo Hanare terdapat empat 
tokoh remaja yang menggunakan adverbia ichiou pada percakapannya dan terdapat juga tokoh orang dewasa yang berusia sekitar 25-35 tahun.

Pada novel Kiokuya I, II dan III, adverbia ichiou juga mendapatkan hasil yang sama dengan analisis novel Reikan kentei bahwa adverbia ichiou digunakan usia remaja dan dewasa. Sesuai dengan hubungan bahasa dengan status sosial yang dikemukakan oleh Kei (2013) bahwa terdapat kecenderungan pada usia remaja dan dewasa menggunakan adverbia yang mengungkapkan makna yang ambigu guna menghindari konflik sehingga banyak yang menggunakan adverbia ichiou.

\section{KESIMPULAN}

Berdasarkan hasil analisis dapat diketahui bahwa adverbia ichiou banyak digunakan oleh pria, juga dapat digunakan untuk semua status dan semua usia namun perlu diperhatikan bahwa status sosial dapat mempengaruhi penggunaan adverbia ichiou dalam suatu percakapan.

Dilihat dari data, penggunaan adverbia ichiou digunakan ketika penutur memiliki status sosial yang setara dengan mitra tutur atau penutur yang memiliki status sosial lebih tinggi dari mitra tuturnya.

\section{REFERENSI}

1. Hymes, D. 1990. Introduction: Toward Ethnographies of Communication 1. American anthropologist, 66(6_PART2 ), $1-34$.

2. Akiko, S. 1998. Discourse

Modality Fukushi/ Ichioo ni Tsuite. Tokyo: Waseda Daigaku Nihongo Kenkyu Kyoiku Senta.

3. Chaer dan Agustina, L. 2004. Sosiolinguistik: Perkenalan Awal. Jakarta: PT Rineka Cipta.

4. Kei I. 2013. Nihongo wa [kuuki] ga Kimeru: Shakaigengogaku Nyumon. Tokyo: Kobunsha.

5. Sachiko dan Harumi T. 1997. Shakai Gengogaku e no Shotai: shakai, bunka, komyunikeshon. Tokyo: Mineruva Shobō

6. Febrianty, F. Setiana, S. M., dan Haryanti, P. 2015. Analisis Kesalahan

Mahasiswa dalam

Penggunaan Keigo (Studi 
Kasus Terhadap Mahasiswa

Program Studi/Jurusan

Sastra/Bahasa Jepang di Kota

Bandung). Bandung: Unikom.

7. Takashi dan Yukinori, T. 1992.

Kiso Nihongo Bunpou. Tokyo:

Kuroshio Publishing.

8. Yasushi, Mizue dan Masami.

1996. Aimai go jiten. Tokyo:

Tokyodo Publishing.

9. Putri, T. A. Y. 2018.

Penggunaan Adverbia Ichiou

dalam Percakapan bahasa

Jepang Sehari-hari (Kajian

Sosiolinguistik). Bandung:

Unikom.

10. Putri, T. A. Y., Kurniawan, S.,

Haryanti, $\quad$ P. 2018.

Penggunaan Adverbia Ichiou

dalam Komponen Tutur

Norms of Interaction and

Interpretation.Bandung 